Lavrinovich R. D.

\title{
«THE PROTOTYPE OF THE OPPOSITION» IN THE REGISTRATION OF TRADEMARKS IN THE RUSSIAN FEDERATION, ITS FEATURES AND NATURE
}

Автором статьи рассматривается действующий порядок регистрации и предоставления правовой охраны товарным знакам в Российской Федерации. Отмечается предложенная федеральным органом исполнительной власти по интеллектуальной собственности в 2015 году процедура оппозиции. Уделяется внимание порядку подачи и природе письменных обращений, подаваемых третьими лицами согласно статье 1493 Гражданского кодекса Российской Федерации, а также рассматриваются случаи подачи данных письменных обращений. Анализируется проект Федерального закона № 509994-7 «О внесении изменений в часть четвертую Гражданского кодекса Российской Федерации» в части, предусматривающей возможность любого лица представить в Роспатент возражение против предоставления правовой охраны географическому указанию или против предоставления исключительного права на использование географического указания.

Ключевые слова: интеллектуальная собственность, средства индивидуализации, товарный знак, наименование места происхождения товара, географическое указание, оппозиция.

The author of the article considers the current procedure for registering and granting legal protection to trademarks in the Russian Federation. Opposition procedure proposed by the federal executive body for intellectual property (hereinafter - Rospatent) in 2015 is noted. Attention is paid to the procedure for filing and the nature of written requests submitted by third parties in accordance with Article 1493 of the Civil Code of the Russian Federation, as well as the cases when these written requests are submitted. The draft Federal Law No. 509994-7 "On Amendments to Part Four of the Civil Code of the Russian Federation» is analyzed, providing for the possibility of any person submitting an objection to Rospatent against granting legal protection to a geographical indication or against granting an exclusive right to use a geographical indication.

Keywords: intellectual property, means of individualization, trademark, appellation of origin, geographical indication, opposition.

В 2015 году федеральным органом исполнительной власти по интеллектуальной собственности (далее - Роспатент) было вынесено предложение изменить процедуру регистрации обозначений в качестве товарных знаков и ввести процедуру оппозиции. Данный порядок предусматривает возложение на данный орган обязанности (в части экспертизы) проведения формальной экспертизы и экспертизы обозначения, заявленного в каче- стве товарного знака (экспертиза заявленного обозначения) по абсолютным основаниям для отказа в регистрации обозначений в качестве товарных знаков. То есть исключаются полномочия Роспатента по проведению экспертизы обозначений на наличие относительных оснований для отказа в регистрации обозначений в качестве товарных знаков. Мониторинг и недопущение регистрации «конфликтных» обозначений, не соответству- 
ющих требованиям законодательства по относительным основаниям, будут осуществлять правообладатели ранее зарегистрированных объектов путем направления в Роспатент своих возражений.

В первую очередь после поступления такого возражения Роспатент будет извещать об этом заявителя спорного обозначения, предоставляя самим сторонам возможность урегулирования спора в определенный срок.

В случае, если по истечении установленного срока спор не будет урегулирован и поданное возражение не будет отозвано, рассмотрение возражения и принятия окончательного решения о государственной регистрации товарного знака или об отказе будет осуществлять Роспатент.

Первый шаг на встречу введения процедуры оппозиции в отечественное законодательство был сделан несколько лет назад путем внесения изменений в статью 1493 Гражданского кодекса Российской Федерации. Итак, был создан «прообраз» оппозиции. Положения данной статьи предоставили возможность любого третьего лица после опубликования сведений по заявке на товарный знак до принятия решения о государственной регистрации товарного знака направить в Роспатент письменное обращение о том, что заявленное обозначение не соответствует требованиям законодательства. Доводы, содержащиеся в обращении, учитываются при проведении экспертизы заявленного обозначения [1].

Стоит отметить, что большая часть таких обращений направляется от правообладателей зарегистрированных товарных знаков, с которыми заявленные на регистрацию обозначения сходны до степени смешения в отношении идентичных или однородных товаров или услуг. То есть поводом для подачи подобных обращений является несоответствие обозначения требованиям пункту 6 статьи 1483 Гражданского кодекса Российской Федерации.

Таким образом, обращения одновременно и «упрощают» работу эксперта в выявлении сходных товарных знаков, и дают правообладателю некую гарантию того, что экспертиза «не пропустит» ваш товарный знак.

При этом заявителями обращений могут быть и обладатели обозначений, незарегистрированных (!) в качестве товарных знаков. В данном случае основанием может являться пункт 3 статьи 1483 Гражданского кодекса Российской Федерации - «не допускается государственная реги- страция в качестве товарных знаков обозначений, представляющих собой или содержащих элементы, являющиеся ложными или способными ввести в заблуждение потребителя относительно товара либо его изготовителя». Зачастую заявители это зарубежные производители идентичных товаров, маркированных тождественными обозначениями, продукция которых хорошо известна не только на местном рынке, но и российскому потребителю, а, следовательно, российский потребитель может быть введен в заблуждение относительно товара и его производителя. Обычно данные лица заявители-обладатели-производители, зарегистрировав товарный знак на территории своей страны, на территории Российской Федерации не регистрирует данный товарный знак, а распространяют свою продукцию через дистрибьютеров или иных официальных представителей, заключая с ними договоры о невозможности регистрации ими данных обозначений на свое имя. К сожалению, данные договоры распространяются лишь на две стороны договора, но не препятствуют третьим лицам зарегистрировать обозначения на свое имя. Конечно же, такая регистрация является нарушением не только пункта 3 статьи 1483 Гражданского кодекса Российской Федерации, но и статьи 10 Гражданского кодекса Российской Федерации, как злоупотребление правом либо акта недобросовестной конкуренции. В случае регистрации подобного обозначения в качестве товарного знака, согласно подпункту 1 и 6 пункта 2 статьи 1512 Гражданского кодекса Российской Федерации предоставление правовой охраны товарному знаку может быть оспорено и признано недействительным. Однако данный процесс занимает значительные временные и финансовые траты, которые зачастую в рамках бизнеса является существенными потерями. К тому же за то время, что существовал «незаконный товарный знак» он мог причинить вред репутации и имиджу обладателю обозначения, в случае если товары или услуги, предлагаемые «нарушителем» обладали негативной характеристикой или качеством.

Данное обращение также будет «полезно» экспертизе, так как, к сожалению, экспертиза не имеет возможности знать обо всех заключенных контрактах, иметь данные о регистрации и использовании обозначений на территории иностранных государствах, а информация в сети Интернет не всегда обладает точной информативностью, которая может быть приня- 
та в качестве достоверного доказательства.

По пункту 3 статьи 1483 Гражданского кодекса Российской Федерации могут быть поданы обращения против регистрации обозначения в качестве товарного знака в отношении определенного вида товаров (чаще всего 32 и 33 классов МКТУ), если, по мнению обращающегося лица, обозначение, регистрируемое на имя, например, российского заявителя, имеет стойкую ассоциацию с иностранным происхождением данного товара. Такая сложившаяся устойчивая ассоциация между, например, определенным словом, включенным в состав заявленного на регистрацию обозначения или полностью представляющего его, и его происхождением может складываться тогда, когда товарные знаки, включающие в себя данное слово, регистрируются на имена правообладателей определенного иностранного государства с целью подчеркнуть происхождение товаров. В связи с этим российские потребители осведомлены о связи слова с товаром и его происхождением. Таким образом, по причине именно такой сильной связи использование и регистрация обозначения в отношении этого товара на имя, например, российского производителя будет с большой долей вероятности вводить потребителей в заблуждение относительно его происхождения, что также может негативно сказаться на бизнесе «реальных» производителей данного товара. Стоит отметить что доводы, содержащиеся в подобном возражении, не «откроют Америку» экспертизе. Однако заявитель может быть спокоен, что изложенное им доводы касательно имеющегося основания для отказа в регистрации заявленного обозначения в качестве товарного знака не останется экспертизой без внимания.

Действующий порядок государственной регистрации наименования места происхождения товара и (или) в предоставлении исключительного права на такое наименование заявителю на данный момент также предусматривает после публикации сведений о заявке и до принятия по ней решения возможность подачи обращений в письменной форме, содержащее доводы против предоставления правовой охраны наименованию места происхождения товара или против предоставления исключительного права на использование наименования места происхождения товара, которые также учитываются экспертизой при вынесении решения.

Необходимо упомянуть, что проект
Федерального закона № 509994-7 «О внесении изменений в часть четвертую Гражданского кодекса Российской Федерации» (ред., внесенная в ГД ФС РФ, текст по состоянию на 13.07.2018) предусматривает возможность любого лица после в официальном бюллетене публикации сведений о принятых к рассмотрению заявках на географическое указание, в течение трех месяцев представить в Роспатент возражение против предоставления правовой охраны географическому указанию или против предоставления исключительного права на использование географического указания.

Исходя из положений данного проекта можно сделать вывод, что данные возражения будут рассматриваться не экспертами в рамках проводимой экспертизы обозначения требованиям законодательства, а в рамках отдельной административной процедуры, порядок которой будет устанавливаться федеральным органом исполнительной власти, осуществляющим нормативно-правовое регулирование в сфере интеллектуальной собственности.

По результатам рассмотрения таких возражений Роспатент будет принимать решение о государственной регистрации географического указания и/или о предоставлении исключительного права на такое географическое указание или об отказе в государственной регистрации географического указания и/или в предоставлении исключительного права на такое географическое указание с учетом результатов экспертизы заявленного обозначения.

Принятие «отказного» решения повлечет отмену решения о государственной регистрации географического указания и (или) о предоставлении исключительного права на географическое указание, вынесенного по результатам экспертизы заявленного обозначения.

Таким образом, согласно предложению законодателей решение о государственной регистрации географического указания будет приниматься на основании решения, принятого по результатам экспертизы заявленного обозначения, и при отсутствии возражений, или по результатам рассмотрения данных возражения.

Примечательно, что в данном случае уже используется не термин «обращение», как в отношении товарных знаков и наименований места происхождения товара, а «возражение».

Подводя итоги, стоит отметить, что эффективная правовая охрана товарных знаков может быть обеспечена только по- 
средством качественной процедурой ее предоставления. Действующая система регистрации обозначений в качестве товарных знаков, суть которой заключается в том, что экспертиза проводится экспертами федерального института промышленной собственности, а также существует возможность любого третьего лица направить обращение о невозможности ре- гистрации заявленного обозначения, неплоха, однако имеет и пробелы и недостатки. Таким образом, самой главной задачей законодателя является не только само изменение законодательства, но и то, чтобы все вносимые изменения в нормативные правовые акты были направлены только на их улучшение, то есть на их совершенствование.

\section{Литература}

1. Гражданский кодекс Российской Федерации (часть четвертая) от 18.12.2006 № 230-Ф3 (ред. от 27.12.2018 № 549-Ф3) // «Парламентская газета», N 214$215,21.12 .2006$

2. Проект Федерального закона № 509994-7 «О внесении изменений в часть четвертую Гражданского кодекса Российской Федерации» (ред., внесенная в ГД ФС РФ, текст по состоянию на 13.07.2018) // [Электронный ресурс] URL: http://www.consultant.ru/cons/cgi/online.cgi?base $=P R J \& n=173604 \&$ req $=d$ oc\#08767207566668125

3. Проект примерной модели процедуры оппозиции // [Электронный ресурс] URL:https://rupto.ru/press/news_archive/inform2016/Proekt_oppozit/ Proekt_oppozit.pdf.

\section{References}

1. Grazhdanskiy kodeks Rossiyskoy Federatsii (chast' chetvertaya) ot 18.12.2006 № 230-FZ (red. ot 27.12.2018 № 549-FZ) // «Parlamentskaya gazeta», N 214-215, 21.12.2006

2. Proyekt Federal'nogo zakona № 509994-7 «O vnesenii izmeneniy v chast' chetvertuyu Grazhdanskogo kodeksa Rossiyskoy Federatsii» (red., vnesennaya $\checkmark$ GD FS RF, tekst po sostoyaniyu na 13.07.2018) // [Elektronnyy resurs] URL: http://www. consultant.ru/cons/cgi/online.cgi? base $=$ PRJ \&n=173604\&req $=d$ oc\#08767207566668125

3. Proyekt primernoy modeli protsedury oppozitsii // [Elektronnyy resurs] URL:https:// rupto.ru/press/news_archive/inform2016/Proekt_oppozit/Proekt_oppozit.pdf.

ЛАВРИНОВИЧ Рада Дмитриевна, аспирант кафедры Авторского права, смежных прав и частноправовых дисциплин, Российская государственная академия интеллектуальной собственности. 117279, РФ, Москва, ул. Миклухо-Маклая, 55A. E-mail: Deabest@yandex.ru

LAVRINOVICH Rada Dmitrievna, post-graduate student, department of Copyright, related rights and private law disciplines, Russian state academy of intellectual property. 117279, the Russian Federation, Moscow, st. MiklouhoMaclay, 55A. E-mail: Deabest@yandex.ru 